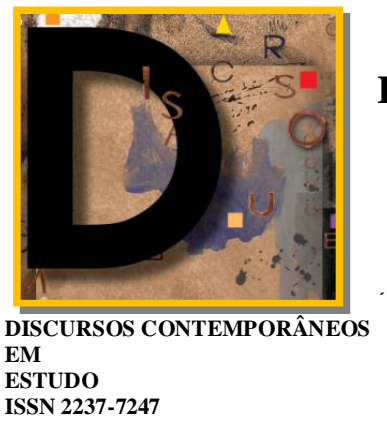

\title{
LETRAMENTO MULTIMODAL E TEXTO EM SALA DE AULA
}

Jardélia Moreira dos Santos $(U n B)^{l}$

Pretendo estabelecer, por meio deste artigo, novas perspectivas para o texto, sob a ótica da Análise de Discurso Crítica (ADC), do Letramento e da Multimodalidade. De acordo com Fairclough (1992, 2001, 2003), Chouliaraki e Fairclough (1999), o entendimento efetivo dos efeitos sociais do texto só é possível se os analisarmos no momento da fala ou da escrita. Kress e van Leeuwen (1996) afirmam que a escrita não mais ocupa o lugar central no panorama comunicacional, por isso, o modo como os professores orientam as práticas discursivas de seus alunos em relação aos textos multimodais pode contribuir para a construção crítica do discurso do aluno. Nesse sentido e, considerando o Letramento, tal qual foi defendido por Street (1984, 1993, 1995), Barton e Hamilton (1998, 2000) e Hasan (1996), proponho uma revisão dessas práticas.

Palavras-chave: Letramento. Multimodalidade. Análise de Discurso Crítica (ADC). Multiletramentos. Semiótica Social.

I intend to establish, by means of this article, new perspectives for the text, under the optics of the Critical Discourse Analysis (CDA); of the Literacy and Multimodality. In accordance with Fairclough (1992, 2001, 2003), Chouliaraki and Fairclough (1999), the effective agreement of the social effects of the text is possible only if we analyze them at the speaking or writing's moment. Kress and van Leeuwen (1996) affirm that the writing does not occupy the central place in the comunicacional panorama any more, so, the way the teachers guide their pupils on the discoursive practices in relation to the multimodal texts can contributes for the critical construction of the speech of the pupil. Considering the Literacy, such which was defended by Street (1984, 1993, 1995); Barton and Hamilton (1998, 2000) and Hasan (1996), I consider a revision of these practical.

Keywords: Literacy. Multimodality. Critical Discourse Analysis (CDA). Multiliteracies. Social Semiotic.

\footnotetext{
${ }^{1}$ Mestre em Linguística pela Universidade de Brasília (UnB); membro do Centro de Pesquisa em Análise de Discurso Crítica.E-mail: jardelia@unb.br.
} 


\section{Introdução}

Meu objetivo neste artigo é estabelecer uma visão de texto na contemporaneidade. Utilizo, aqui, texto, como Fairclough (2003), em sentido amplo: qualquer exemplo de linguagem em uso é um texto. Considerando que textos são partes de eventos sociais, alguns elementos têm caráter altamente textual, outros, não. Assim, textos impressos e escritos, como listas de compras e artigos de jornal, são textos; cópias de conversas e de entrevistas (faladas) também o são, assim como televisão e páginas na internet.

Considero também que, as imagens carregam uma significação cultural com marcas geográficas, religiosas e sociais que permitem ao leitor múltiplas e infinitas possibilidades de leitura. Ler essas semioses, interpretando-as como um texto verbal, é um desafio que se corporifica neste mundo, marcado pela proliferação de imagens que nos bombardeiam: outdoors, noticiários, propagandas, multimídia.

Qualquer que seja o texto escrito, ele é multimodal, composto por mais de um modo de representação. Além de palavras, elementos não verbais, como fotos, desenhos, tabelas, gráficos, quadros, diagramação da página (layout), interferem na mensagem a ser comunicada; bem como a cor e a qualidade do papel, o formato e a cor (ou as cores) das letras e a formatação do parágrafo.

\section{Bases Teóricas}

A Análise de Discurso apresenta duas vertentes: crítica e não crítica. A linha de Análise de Discurso Crítica (ADC) possui como diferencial a ênfase sobre a esfera da prática social. Esta linha confere à linguagem um papel central e dependente dos determinantes culturais e das estruturas de poder que a configuram no contexto social.

Atualmente, ADC torna-se um projeto transdisciplinar com perspectivas sobre a linguagem e o discurso imersos na teoria e pesquisa sociais para desenvolver a capacidade de analisar textos como elementos do processo social. A transdisciplinaridade à teoria ou ao método analítico encontra-se em trabalhar com categorias sociológicas para não enfocar somente as propriedades discursivas (produção, distribuição e consumo dos textos) e textuais, mas, sim, para vê-las como prática social nas instituições e nas relações com o poder e com os projetos hegemônicos da sociedade.

Fairclough (2003) afirma que a Análise de Discurso é influenciada pela obra de Foucault e que representa uma importante contribuição para uma teoria social do discurso em áreas, como a relação entre discurso e poder, a construção discursiva de sujeitos sociais e do conhecimento e o funcionamento do discurso na mudança social. Para uma análise com base nos significados representacionais, Fairclough (2003) propõe, contudo, categorias diferentes: os processos, os 
participantes e as circunstâncias. É necessário, ainda, considerar relações sociais e formas institucionais, objetos, meios e tecnologias, linguagem (e outros tipos de semiose).

Os processos, normalmente, realizam-se sob a forma de verbos; os participantes, sob a forma de sujeito, objetos diretos ou indiretos; e as circunstâncias, sob a forma dos diferentes tipos de elementos adverbiais, como adjuntos adverbiais de tempo ou lugar. A relevância de análise dessas três categorias é observada por Fairclough (2003, p. 135-136):

Para analisar os textos, sob a perspectiva representacional, é necessário verificar quais processos, participantes e circunstâncias estão incluídos na representação dos eventos observados, quais dos elementos foram excluídos, aos quais foi dada maior importância; se o evento social está representado de forma concreta ou abstrata e qual é o nível de generalização do mesmo (FAIRCLOUGH, 2003, p. 135-136).

Os participantes podem ser identificados como agentes ou pacientes no processo. Podem ser representados pessoal ou impessoalmente, pelo nome (nomeados) ou classificados, de acordo com as categorias a que pertencem; podem, ainda, referir-se a um grupo específico ou a uma classe em geral. Os agentes podem estar excluídos ou incluídos no texto, podendo vir sob a forma de substantivos ou pronomes, usados anaforicamente para fazer referência a algo já citado.

Os processos dizem respeito ao modo como os participantes agem nos eventos sociais; as pessoas são os agentes que podem estar incluídos ou excluídos; as relações sociais e as formas institucionais representadas podem ser mencionadas ou não. Os objetos e os meios relacionam-se com a linguagem dos tipos de eventos e podem estar ou não suprimidos no texto.

A análise de texto é parte importante para Análise de Discurso, porém, esta não é apenas a análise linguística de textos, mas algo que oscila entre o foco em textos específicos e o foco em ordens de discurso, que é a estruturação social de uma língua e sua parceria com determinadas práticas sociais. A ADC, por sua vez, além de ser linha teórica é também modelo de análise e por isso foi escolhida para nortear o meu trabalho.

\section{Letramento em revisão}

Os estudos tradicionais de linguagem concebiam a língua como entidade de dupla face, cuja manifestação, ou se realizava pela oralidade, ou pela escrita. Tal dicotomia foi substituída, na década de 80, pela noção de continuum. Segundo Tannen (1982), havia uma superposição dos dois sistemas; fala e escrita interagiam frequentemente. 
Street (1995) critica essas abordagens pelo fato de o estudo das atividades de linguagem ser isolado e descontextualizado. Para ele, a escrita é, antes de tudo, prática social. Essas críticas provocaram o surgimento das novas perspectivas, intituladas de Letramento. Nesse sentido é que

A escrita, na concepção do Letramento, não é conhecimento adquirido de modo solitário e individual, pois é o produto de práticas sociais de escrita de determinada cultura (VIEIRA, 2003, p. 253).

Letramentos são baseados em sistemas simbólicos usados para comunicação e como tais existem em relação de troca com outros sistemas de informação. Nessa perspectiva, para refletir sobre o valor simbólico e constitutivo da leitura e da escrita em uma sociedade letrada, é preciso, conforme os novos estudos do Letramento, considerar que leitura e escrita só constituem sentido se imersas nas práticas sociais do contexto social em geral e da cultura em particular.

Diferentes culturas valorizam e aprendem diferentes formas de Letramento. Os variados letramentos na vida das pessoas representam tensões, misturam valores. Para Barton e Hamilton (1998) letramentos criam novas identidades e reconciliam conflitos sobre mudanças de valores. Existem muitos padrões de como o Letramento é distribuído entre os participantes em diferentes relacionamentos com o outro. Ele está associado, portanto, às diferentes identidades .

Letramentos não são apenas as habilidades de ler e de escrever, nem estão ligados apenas à esfera do ensino, são fenômenos sociais de escrita e de linguagem. Crianças adquirem língua e Letramento no meio em que convivem (família, igreja, vizinhança, escola, parquinho, clube), e a escola é o fórum adequado de interação. De acordo com Kleiman (1995), a escola é, em quase todas as sociedades, a principal agência de Letramento.

A escola, a família, a igreja, a vizinhança mostram orientações diferentes para o Letramento. Todos os grupos possuem práticas sociais que dão origem a habilidades específicas em suas crianças. Entretanto, apenas algumas dessas habilidades, culturalmente determinadas, são privilegiadas na escola, pois a língua e seu uso são resultados de forças sociais.

É impossível investigar Letramento sem referência direta ao papel da fala e da escrita no contexto contemporâneo. Não se podem observar as semelhanças e as diferenças entre elas sem considerar seus usos nas práticas sociais. A fala manifesta-se naturalmente em contextos informais do dia a dia e nas relações sociais e dialógicas que se instauram desde o momento em que a mãe dá seu primeiro sorriso ao bebê.

Marcuschi (2004) define fala como uma forma de produção textual-discursiva para fins comunicativos na modalidade oral, sem a necessidade de outra tecnologia além do aparato disponível pelo próprio ser humano. Ele aponta a oralidade como uma prática interativa para fins comunicativos 
que se apresenta sob variadas formas ou gêneros textuais fundados na realidade sonora e que vai desde realizações mais informais às mais formais, nos mais variados contextos.

A influência da escrita, por sua vez, é marcante porque, no cotidiano, é usada em múltiplos contextos sociais, quais sejam: o trabalho (inclusive o intelectual), a escola, a família. É caracterizada por sua constituição gráfica, embora envolva, às vezes, elementos imagéticos, ideográficos e pictóricos.

Letramentos, como práticas sociais, são formalmente ligados ao uso da escrita, a qual se tornou um bem social indispensável para enfrentar o dia-a-dia quer seja nos centros urbanos, quer seja na zona rural. Essas práticas variam desde uma apropriação mínima da escrita, até uma apropriação profunda (STREET, 1995, p. 2).

Marcuschi (2004) propõe que os analfabetos também estão sob a influência do que se convencionou chamar de práticas de Letramento, isto é, processos histórico-sociais que não se confundem com a realidade representada pela alfabetização regular e institucional.

\section{Alfabetização, escolarização e letramento}

Embora a alfabetização não seja pré-requisito para o Letramento, ele está relacionado com a aquisição e a utilização das funções da leitura em práticas sociais. Está relacionado, também, à escolarização, que abrange processos educativos. Portanto, antes de iniciar a discussão sobre Letramento, faço uma distinção entre tais fenômenos.

A alfabetização é sempre uma aprendizagem mediante ensino e compreende o domínio ativo e sistemático das habilidades de ler e escrever. A escolarização, por sua vez, é uma prática formal e institucional de ensino que visa à formação integral do indivíduo (MARCUSCHI, 2004, p. 24-25).

Hasan (1996) sugere que, devido à multiplicidade de significados atribuídos, o Letramento é um processo multifacetado, seguindo fenômenos de diferentes tipos. Controvérsias, porém, tendem a assumir que somente algum aspecto seja relevante; os outros podem ser ignorados. 


\section{Eventos e Práticas: componentes do letramento}

Heath (1982) foi quem primeiro usou o termo evento de Letramento e o definiu como situações em que a língua escrita é parte integrante da natureza da interação entre participantes e de seu processo de interpretação. Essa interação tanto pode ocorrer oralmente, com a mediação da leitura e da escrita, com os interlocutores face a face, ou a distância, com a mediação de um texto escrito.

Práticas de letramento são ocasiões em que a escrita (e/ou leitura) é parte constitutiva das interações dos participantes e de seus processos e estratégias interpretativas, isto é, são ocasiões em que as palavras, quer sejam elas faladas, [quer] sejam escritas, são usadas em uma interação social concreta (HEATH, 1983, p. 76).

Levando-se em consideração a definição de Heath, os usos da leitura e da escrita são analisados em contextos contínuos e reais; assim, os eventos passam a ser situações comunicativas mediadas por textos escritos. O fenômeno do Letramento, então, extrapola o mundo da escrita.

Para Street (1995), práticas são, tanto os comportamentos exercidos pelos participantes em um evento de Letramento, quanto as concepções sociais e culturais que o configuram. Elas determinam sua interpretação e dão sentido aos usos da leitura e/ou escrita naquela particular situação.

Nessa dimensão social, os eventos e as práticas de Letramento são plurais, são as duas faces de uma mesma realidade. Barton e Hamilton (2000) definem práticas de Letramento como os caminhos culturais comuns de utilização da linguagem escrita com que as pessoas delineiam suas vidas. As práticas envolvem valores, atitudes, sentimentos e relações sociais que se tornam observáveis por meio de eventos.

- Letramento é melhor entendido como um conjunto de práticas sociais, que podem ser inferidas de eventos mediados por textos escritos.

- Há diferentes Letramentos associados a diferentes domínios da vida.

- As práticas são padronizadas pelas instituições e pelas relações de poder, alguns Letramentos são mais dominantes, visíveis, influentes que outros.

- Letramento é historicamente situado.

- Práticas mudam e novas práticas são frequentemente desenvolvidas por meio de processos informais de aprendizagem e da produção de sentidos.

Fonte: BARTON; HAMILTON, 2000, p. 8. 
Para Heath (1982, p. 52),

Eventos são atividades em que o Letramento tem uma função, normalmente há um texto escrito, ou textos, isto é, são situações em que a escrita constitui parte essencial para fazer sentido da situação, tanto em relação à interação entre os participantes como em relação aos processos e às estratégias interpretativas, o que é central para a atividade.

Eventos são episódios observáveis que se originam das práticas e são moldados por elas. As práticas específicas da escola passam a ser, em função dessa definição, apenas um tipo de prática, que desenvolve apenas alguns tipos de habilidades, principalmente as que privilegiam a escrita. Para tentar compreender melhor as práticas de uso da escrita da escola, Street (1984) propõe o binômio Modelo Autônomo e Modelo Ideológico.

\section{Binômio de Street}

Estudos de Street $(1984,1993,1995)$ propõem o binômio Modelo Autônomo e Modelo Ideológico para discutir as práticas de Letramento na escola e a relação que se estabelece entre o modelo subjacente a essas práticas e o sucesso ou o fracasso na construção de contextos facilitadores de transformação dos alunos em sujeitos letrados. Segundo Street (1994, p. 5),

o Modelo Autônomo é um Letramento independente do contexto social, uma variável autônoma cujas consequências para a sociedade podem ser derivadas do seu caráter intrínseco. Assim, a autonomia refere-se ao fato de que a escrita seria completa em si mesma, ou seja, não estaria presa ao contexto de sua produção para ser interpretada.

O Modelo Autônomo discrimina a linguagem oral. É apresentado de forma subjacente à ideia de que a linguagem escrita é mais importante que a falada e que, portanto, quem domina a escrita tem status superior na sociedade. O conservadorismo do Modelo Autônomo atribuía ao aluno o fracasso escolar, pois o considerava incapaz de desenvolver os conhecimentos necessários para obter o sucesso e a promoção.

Neste modelo, práticas de leitura e de escrita (aparentemente neutras) são trabalhadas desvinculadamente do contexto social, como algo independente, valorizando o ato cognitivo em si e as competências de ler e de escrever. Isso reforça a divisão das pessoas envolvidas nessas práticas em dois grupos: letradas (superiores e dominadoras) e iletradas (inferiores e dominadas). Porém, essa concepção recebeu inúmeras críticas, entre elas: correlação entre a aquisição da escrita e o 
desenvolvimento cognitivo; dicotomização entre a oralidade e a escrita; atribuição de poderes e de qualidades intrínsecas à escrita e, por extensão, aos povos ou aos grupos que a possuem.

As práticas de uso da escrita na escola sustentam-se neste modelo de Letramento, que é considerado, por muitos pesquisadores, contudo, tanto parcial, quanto equivocado. A escola sempre pautou o ensino pela progressão ordenada de conhecimentos: aprender a falar a língua dominante, assimilar as normas do sistema de escrita para fazer uso desse sistema em formas de manifestação previsíveis e valorizadas pela sociedade. Conforme Street (1995, p. 7),

o Modelo Ideológico de Letramento sustenta as seguintes asserções: a linguagem escrita é uma prática social marcada por relações de poder, portanto ideológicas, e ligada a interesses políticos e econômicos; os aspectos sociais ligados à classe, ao gênero social, à etnia a aos grupos etários em relações de poder e presentes nas práticas discursivas devem ser considerados e analisados criticamente; as práticas sociais de linguagem são mantidas pela ideologia a serviço da dominação.

O Modelo Ideológico de Letramento não separa a oralidade da escrita como faz o Modelo Autônomo. Trabalha com práticas de Letramento em um processo de socialização do indivíduo, no qual as práticas discursivas acontecem não apenas na instituição escolar, mas em todo e qualquer contexto no qual o indivíduo possa interagir; admite, ainda, a pluralidade das práticas letradas, valorizando o seu significado cultural e o contexto de produção.

Rompendo definitivamente com a divisão entre o momento de aprender e o momento de fazer uso da aprendizagem, os estudos linguísticos propõem a articulação dinâmica e reversível entre descobrir a escrita (conhecimento de suas funções e de suas formas de manifestação); aprender a escrita (compreensão das regras e dos modos de funcionamento) e usar a escrita (cultivo de suas práticas, partindo de um referencial culturalmente significativo para o sujeito).

Street (1993) destaca o fato de que todas as práticas de Letramento são aspectos não apenas da cultura, mas também das estruturas de poder em uma sociedade. Ao falar de práticas, no plural, já se estabelece o diferencial entre o Modelo Ideológico e o Modelo Autônomo. Este apresenta apenas um tipo de Letramento, o neutro. Aquele considera a pluralidade e a diferença, valorizando o aluno em si mesmo e em seu contexto sociocultural, pois as práticas são social e culturalmente determinadas, sendo, portanto, múltiplas. Nele, não se pressupõe relação causal entre Letramento e progresso ou civilização, pois, em vez de estabelecer distinção entre oralidade e escrita, propõe a interface entre tais práticas. Street (1984) aponta a existência de práticas de Letramento específicas de grupos considerados, na perspectiva do Modelo Autônomo, iletrados ou com baixo grau de Letramento. 
A noção de diferentes Letramentos tem vários sentidos. Práticas que envolvem diferentes mídias e sistemas simbólicos, assim como filmes ou computadores, podem ser classificadas como diferentes Letramentos. Outro sentido é que as práticas em diferentes culturas e linguagens podem ser consideradas como diferentes Letramentos.

O termo Letramento remete à dimensão complexa e plural das práticas sociais de uso da escrita - a apreensão de dada realidade -, seja ela de determinado grupo social ou de campo específico de conhecimento (ou prática profissional), o que motivou a emergência de inúmeros estudos a respeito de suas especificidades. Por isso, nos meios educacionais e acadêmicos, surgiu a referência no plural, Letramentos.

\section{Multiletramentos: um novo conceito}

Para o enriquecimento da multiplicidade de Letramentos, o ensino de Língua Portuguesa não pode prescindir da análise imagética, pois há muitos eventos de Letramento que apresentam não só linguagem escrita e falada, mas também diferentes sistemas semióticos.

Essa afirmação abre possibilidades para um Letramento calcado na leitura e na escrita e na sua ampliação, tendo em vista que as práticas efetivas estão ligadas a modos culturais mais amplos e, nestes, estão as imagens que circulam no contexto sociocultural. Não ser letrado em comunicação visual poderá acarretar sanções sociais. O chamado Letramento visual será questão de sobrevivência.

Para Barton e Hamilton (2000), é possível falar agora em Multiletramentos, como o computacional, o visual, o científico, o musical, o escolar, o social, o tecnológico. Portanto, não existe forma única de Letramento, mas múltiplos Letramentos, presentes em seus contextos sociais e culturais nas sociedades em que surgem, considerando-se também as relações de poder ali existentes.

Embora a escrita tenha sido o mais valorizado meio de comunicação nos últimos séculos, outros meios de comunicação sempre existiram. Kress e van Leeuwen (1996) defendem que a comunicação sempre foi multimodal, e o que está acontecendo, atualmente, apesar de não ser nada novo, ainda assim, é uma mudança significativa e que hoje parece haver uma instância de novo código de texto e imagem em que a informação é transmitida diferentemente pelos dois modos.

Para Trevisan (2002), a teoria da ação comunicativa permite conduzir a discussão sobre o fluxo da imagem da comunicação para o campo da linguagem. Por meio do caminho da análise imagética, é possível resgatar formas expressivas de tradição, na perspectiva de que a noção da imagem não é entendida como representação de um objeto, mas como signo, algo capaz de ser percebido como um outro objeto com habilidade de produzir realidade. 
Kress e van Leeuwen (1996) analisam que essa nova situação e sua representação não é menos complexa ou de menor demanda cognitiva: é uma relação de complexidade e demanda cognitiva diferentes. Na era da imprensa, o livro era considerado o principal meio de divulgação de informação e mantinha elo indissolúvel com a concepção ocidental de conhecimento. O livro antigo era lido do começo ao fim (focalizava ação física externa, com outros modos semióticos). Atualmente, o livro texto não mantém esse sentido; ele funciona mais como kit de recursos. Assim, é necessário formular novas teorias que possam explicar e descrever os diferentes modos de representação.

\section{Teoria de Representação}

As teorias linguísticas existentes não conseguem explicar satisfatoriamente as mudanças semióticas que estão caracterizando o presente e, provavelmente, o futuro próximo. Se as línguas escrita ou falada não são mais as modalidades semióticas centrais, as teorias da linguagem podem explicar apenas parte do panorama comunicacional e descrever as inter-relações dos diferentes modos de comunicação, incluída a imagem, caracteristicamente utilizados nos textos da contemporaneidade.

Assim, uma teoria adequada para as formas textuais multimodais contemporâneas precisa ser formulada de modo a permitir a descrição de características específicas de uma modalidade em particular e as propriedades semióticas gerais que permitem relacioná-la, de forma plausível, a outras modalidades semióticas. Para Kress e van Leeuwen (1996, p. 6),

\footnotetext{
a representação é vista como um processo em que o produtor de signos, seja adulto ou criança, busca fazer a representação de algum objeto ou entidade, seja física ou semiótica, e que revela seu interesse pelo objeto a ponto de fazer a representação, saindo do contexto cultural, psicológico e social do produtor de signos e focada em um contexto específico no qual o signo é produzido. $\mathrm{O}$ signo é, pois, o ponto-chave em qualquer teoria semiótica.
}

Segundo Kress e van Leeuwen (1996), as duas últimas décadas presenciaram mudança bastante abrangente na mídia e nos modos de comunicação. Os periódicos da década de 60 eram impressos em preto e branco, e cobertos de caracteres escritos; a partir da década de 90, são coloridos, cheios de imagens. Em muitos deles, principalmente no ocidente, os caracteres escritos têm quase desaparecido das páginas. Nos telejornais da década de 60, a tela era tomada pela figura do locutor; as notícias eram apenas eventos linguísticos, mesmo na televisão. Agora, apresentador é o termo utilizado. As notícias ainda possuem elementos verbais, mas a tarefa do mediador mudou de 
leitura para apresentação. A notícia televisiva passa a informação, principalmente, na forma de imagens. O som (não o da leitura ou de comentários verbais, mas a trilha sonora, a música, o barulho do ambiente) também é outro elemento importante. O cenário da comunicação, a partir dos anos 90 , é irrefutavelmente multimodal. Kress e van Leeuwen (1996) nomeiam esse texto multimodal como aquele cujos significados se realizam por mais de um código semiótico .

Kress, Leite-Garcia e van Leeuwen (2000) desenvolveram maneiras de compreender as características dos textos multimodais com base em dois momentos: analisar os principais modos de representação, como o visual, o gestual e o sonoro, em virtude dos quais determinado texto se realiza e produz; e determinar as origens sociais, as marcas da política, das lutas de poder e os distintos interesses daqueles que os produzem. Os autores partem da hipótese de que modos específicos de comunicação - o visual, o gestual, o sonoro - têm potencialidades de significação, mas também, limitações.

A Multimodalidade dos meios linguísticos, em que estamos mergulhados hoje, é assunto que não pode passar despercebido pela escola em qualquer nível de ensino. É impossível ler prestando atenção apenas na mensagem escrita. Esta é apenas um elemento representacional que coexiste com uma série de outros. Elementos como a formatação e o tipo de informação advindos de quaisquer modos representacionais e comunicacionais que ocorrem em um texto devem ser observados, pois, dentro de um determinado domínio sociocultural, os mesmos significados podem frequentemente ser expressos em diferentes modos semióticos, conforme enfatizam Kress e van Leeuwen (1996).

Kress, Leite-Garcia e van Leeuwen (2000) postulam que, se os seres humanos produzem e comunicam significações em vários modos, somente a linguagem não é o bastante para concentrar a atenção de quem está interessado na produção e na reprodução social da significação. Assim, se os textos são sempre multimodais, resulta problemático ler a significação transmitida de modo apenas linguístico. A concepção de que o texto é determinantemente significativo em função de leituras específicas e resistente a outras leituras não apresenta posição atualmente aceita, pois significa que o poder do leitor está limitado pelas formas do texto que lê, assim como também é limitado o poder do escritor. Do ponto de vista semiótico, escrever e ler são atos produtores de signos: escrever é o ato de produzir signos exteriormente visíveis e comunicáveis; ler é o ato de produzir signos interiormente perceptíveis e não comunicáveis.

Assim, a leitura é ativa e transformadora, da mesma forma que a escrita. A leitura está sujeita a restrições, como a escrita que está limitada pelos meios disponíveis para produzir signos e pelas restrições do alcance da ação dos leitores em sua reconstrução. A leitura e a escrita diferem nas possibilidades de comunicação, como também nas consequências cognitivas, culturais e sociais. Se, por exemplo, as possibilidades de comunicação são limitadas para uma pessoa em relação àqueles 
que a rodeiam, suas oportunidades de participar plenamente da vida política, social e cultural também são limitadas.

Em consequência, as significações daqueles que dominam os meios de produção e difusão de significados continuarão dominando. O interesse do produtor do signo no momento da produção é que o levará a escolher a melhor forma (significante) de expressar o que deseja.

\section{Categorias para Análise do Modo Visual}

Cada modo semiótico tem potencialidade para representar e comunicar significações, para formar signos motivados em relação aos níveis comunicativos. Assim, são necessárias algumas categorias para a análise do modo visual, de forma que a composição concatene os significados representacionais e interativos da imagem entre si por meio de três sistemas inter-relacionados:

1. Valor da Informação: a localização dos elementos dota-os de valores informacionais específicos vinculados às várias zonas da imagem ${ }^{2}$ :

a. eixo horizontal: o Dado e o Novo: Dado - o lado esquerdo parece ser o lado da informaçãochave, à qual o leitor (viewer) deve prestar atenção particular; algo que se presume que o leitor já sabe, como parte de sua cultura; o Novo - o lado direito é o novo, a mensagem, o que está em questão, algo que ainda não é conhecido, ou ainda não é familiar para o leitor.

b. eixo vertical: o Real e o Ideal: a seção inferior (bottom) tende a ser mais informativa e prática, mostrando o que é o Real; a seção superior (top) tende a um apelo emotivo e nos mostra o que pode ser; o Ideal.

2. Saliência/projeção: grau pelo qual um elemento propicia atenção a si mesmo; os elementos são designados para atrair a atenção do espectador para diferentes graus, tais como:

a. localização em primeiro ou segundo plano;

b. tamanho relativo;

c. contraste em cores;

d. diferenças de nitidez.

3. Framing: presença ou ausência de mecanismos de enquadramento, que são concebidos por elementos que criam linhas divisórias, conecta ou desconecta os elementos da imagem, de alguma maneira.

Tais princípios não são apenas aplicados às imagens avulsas. Também o são a visuais complexos que combinam texto e imagem, e talvez até outros elementos gráficos.

\footnotetext{
${ }^{2}$ As relações Dado-Novo e Real-Ideal podem estruturar as associações, tanto de uma composição textual, quanto entre texto e imagem.
} 
A discussão, na realidade, é que, depois de um período de duzentos ou trezentos anos de dominação de linguagem escrita como o meio de comunicação e de representação, está havendo, agora, mudança profunda no sistema de mídia, nos modos de representação e na comunicação, bem como no seu sistema de valoração. O cenário semiótico está sendo refeito.

\section{Corpus}

O corpus do estudo de que trata este artigo é composto por um texto multimodal coletado durante a pesquisa de campo, em uma aula de Língua Portuguesa, por apresentar construção de sentido com base nos modos linguístico e imagético nele empregados. Também fizeram parte dos dados coletados o questionário e as notas de campo. Os dados estão organizados em dois conjuntos, de acordo com os instrumentos de coleta específicos:

1. notas de campo: relatos provenientes de contatos com os sujeitos da pesquisa e registros das observações dos estudos de textos multimodais conduzidos pelas professoras em sala de aula.

2. questionário: perguntas aplicadas às professoras com o intuito de obter respostas sobre o conhecimento delas acerca das teorias trabalhadas: ADC, Letramento e Multimodalidade.

\section{Metodologia}

Segundo Flick (2004), as ideias centrais que conduzem a pesquisa qualitativa diferem daquelas empregadas na pesquisa quantitativa. Esta lida com números, usa modelos estatísticos para explicar os dados e é considerada pesquisa hard, ao passo que aquela evita números, lida com interpretação das realidades sociais e é considerada pesquisa soft, conforme o seguinte quadro:

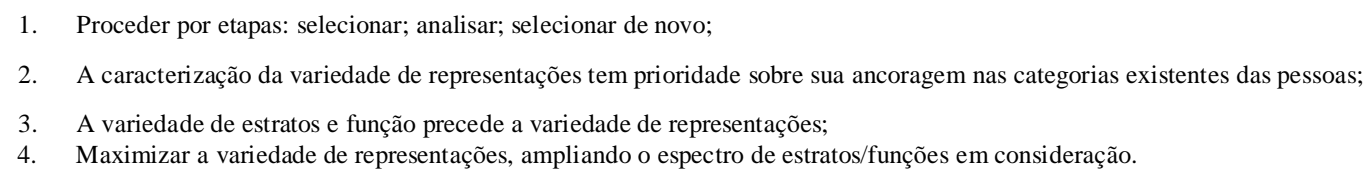

Quadro 2 - Regras para a utilização da pesquisa qualitativa

Fonte: BAUER; GASKEL, 2003, p.22.

Primeiramente o espaço social foi desdobrado em duas dimensões: estratos e representações. Os estratos sociais (funções e categorias) são grau de escolarização, atividade ocupacional e ambiente urbano. Dessa forma, analisa-se o ambiente social da instituição educacional quanto à representação. 


\section{Categorias Analíticas}

Houve a maximização da variedade do fenômeno, neste caso, Letramento multimodal e texto em sala de aula, em que serão mostradas as diferenças nas opiniões, conforme os estratos já apresentados.

1. Fairclough $(2001,2003)$, com a análise linguística, na dimensão do vocabulário em relação ao sentido da palavra e à metáfora; e na dimensão da gramática, no que tange à passivização e à nominalização.

2. Fairclough (2003), com os elementos principais das orações, referentes às representações dos eventos sociais:
a. processos;
b. participantes;
c. linguagem.

3. Kress e van Leeuwen (1996), com as categorias de análise da gramática de construção sintático-visual, dos quais destaco:

a. valor da informação:

- eixo horizontal (Dado x Novo)

- eixo vertical (Real x Ideal)

4. Barton e Hamilton (2000) e Street (1984, 1993, 1995), com a identificação de orientações quanto ao enfoque individual (autônomo) ou social (ideológico) do Letramento.

\section{Em busca de respostas}

Selecionei o enfoque qualitativo por julgá-lo o mais adequado para responder a alguns questionamentos:

1. que modelo de Letramento subjaz às práticas discursivas adotadas pelas professoras?

2. a prática de sala de aula potencializa o aluno para a leitura de textos multimodais?

3. esse trabalho contribui para a construção crítica do discurso do aluno?

O período de coleta de dados foi dividido em dois momentos: de 7 a 11 de março de 2005 e de 17 de maio a 16 de setembro de 2005. No total, foram realizadas vinte visitas à escola, correspondentes a um total de aproximadamente vinte horas de coleta de dados. 


\section{O texto imagético no domínio institucional}

Quatro textos que utilizam a imagem como elemento principal foram explorados em sala de aula pelas professoras. Todos estão no livro didático de Português: FRASCOLLA, A.; FÉR, A.S.; PAES, N.S. Lendo e interferindo, $7^{\text {a }}$ série. São Paulo: Moderna, 1999.

Selecionei o Texto 1 (T1) para análise, por ser composto por mais de um modo de representação em que são utilizados dois tipos de linguagem, a verbal e a visual, de modo que uma serve de apoio ou reforço à outra. Trata-se de uma propaganda sobre o projeto Leia Brasil, da Petrobrás/Ministério de Minas e Energia e apresenta uma imagem que mostra crianças escalando uma montanha de livros, utilizando-se de um fio. Intitulado Projeto Leia Brasil, o texto refere-se a um projeto do Governo Federal para incentivar as crianças a terem o gosto pela leitura. Há um único parágrafo, ocupando aproximadamente um quinto da página.

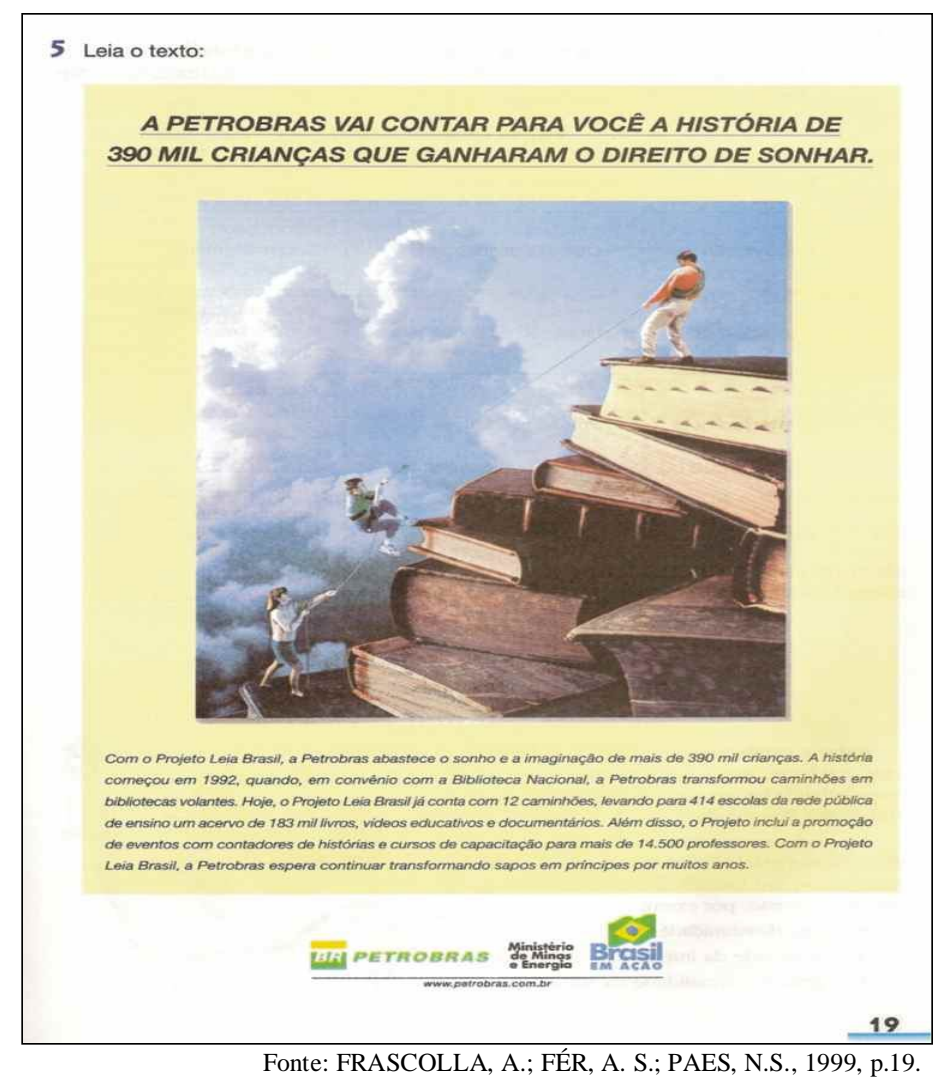




\section{Os resultados: a análise do corpus}

Em relação à parte linguística, foram utilizadas as categorias propostas por Fairclough (2001, 2003), sob os focos do vocabulário e da gramática, especialmente no que tange à passivização e à nominalização que se aplicam à prática social em que se situa o discurso.

A categoria analítica do vocabulário, em relação ao sentido da palavra e à metáfora, considera que qualquer escolha vocabular feita em um texto é intencional e leva a um tipo de construção específica.

Em T1, o significado-potencial das palavras é comum aos usuários da Língua Portuguesa, pois os produtores querem expressar significados que sejam compreensíveis a todos: projeto, história, caminhões, escola, ensino, livros.

Essa escolha do léxico é ideológica, uma vez que, apresenta uma carga semântica comum à natureza do tipo de relação social presente no texto: "a Petrobrás abastece". O termo é significativo e correlaciona-se à atividade específica da Petrobrás. O sentido metafórico é o da própria figura que retrata o esforço e o empenho dos jovens ao escalar a "montanha" de livros.

Em T1, todas as orações são declarativas (afirmativas) e os sujeitos são temas das orações:

1. “a Petrobrás abastece o sonho e a imaginação de mais de 390 mil crianças".

2. "A história começou em 1922”.

3. "O Projeto Leia Brasil já conta com 12 caminhões".

Além disso, os agentes A Petrobrás e o Ministério de Minas e Energia são representados na forma ativa, não há apagamento do agente da ação verbal em:

1. “com o Projeto Leia Brasil, a Petrobrás abastece o sonho e a imaginação de mais de 390 crianças".

2. "além disso, o Projeto inclui".

3. "a Petrobrás transformou".

O autor de T1 apresenta todos os agentes envolvidos, indo em direção a um objetivo. Para tanto, evidencia os processos de ação ao usar as expressões:

1. "a Petrobrás abastece";

2. "a Petrobrás transformou";

3. "o Projeto inclui";

4. "a Petrobrás abastece o sonho e a imaginação";

5. "a Petrobrás transformou caminhões em bibliotecas volantes";

6. "o Projeto inclui a promoção de eventos com contadores de histórias".

Os produtores do texto, Petrobrás e Ministério de Minas e Energia, estão claramente identificados. As instituições são representadas pelos nomes: 
1. "a Petrobrás abastece o sonho e a imaginação de mais de 390 mil crianças";

2. “o Projeto inclui a promoção de eventos".

Como é demonstrado pelo autor de T1, a linguagem utilizada faz parte de um campo semântico comum, por meio da associação de um empreendimento público com qualidades culturalmente valorizadas:

\section{1. "acervo de $\mathbf{1 8 3}$ mil livros, vídeos educativos e documentário”; 2. “a promoção de eventos".}

De acordo com as categorias de análise da Gramática Visual descritas por Kress e van Leeuwen, o texto objetiva trazer a visão de que, quando falamos de texto, identificamos um uso da linguagem (verbal ou não verbal), e que cada modo tem potencialidade para representar e comunicar significações.

No que diz respeito ao valor dado à informação, T1 é estruturado ao longo do eixo vertical: a seção superior (top) tende a um apelo emotivo, visualiza a promessa do sonho, da fantasia, o status que o produto pode conferir a seus usuários (alunos); enquanto a seção inferior (bottom) contém informações mais específicas a respeito do Projeto Leia Brasil.

Quanto ao enfoque social do Letramento, linguagem é uma prática social marcada por relações de poder, portanto ideológicas e ligadas a interesses políticos e econômicos. T1 apresenta uma série de atividades empreendidas pelo Governo Federal em prol dos menos favorecidos para que todos tenham acesso à leitura.

A professora promoveu a análise da imagem e do texto, possibilitando que os alunos fizeram suas inferências em relação à leitura da imagem. Em seguida, estes foram solicitados a produzir uma narrativa contando a história de uma pessoa (criança ou adulto) que ganhou o direito de sonhar por ter acesso aos livros. A professora orientou que, ao iniciar a escrita, os alunos teriam de se preocupar apenas com a criatividade e que, após a primeira escrita, deveriam refazer o texto, buscando o aprimoramento com base em uma ficha de interferências. O aluno deveria registrar as suas ideias, considerando apenas originalidade e criatividade; após, deveria ser feita outra leitura e uma segunda escrita, colocando o texto na ordem de uma redação: introdução, desenvolvimento e conclusão. Antes da versão final, os alunos deveriam eliminar as redundâncias, as repetições, os vícios de linguagem; corrigir possíveis erros ortográficos, de acentuação e verificar se foram feitas as devidas concordâncias.

Os itens vocabulário e gramática não foram tratados na análise durante a aula. As categorias da ADC, como processos, participantes e linguagem não foram abordadas. Os participantes estão incluídos, porém, não foram observados pelos leitores.

A professora dá prioridade à leitura da imagem, mas a visão da Multimodalidade e do valor da informação não chegam a ser trabalhadas. O layout da página, que foi estrategicamente montado 
pelo produtor do signo, não foi observado durante a aula. Além da manchete A PETROBRÁS VAI CONTAR PARA VOCÊ A HISTÓRIA DE 390 MIL CRIANCAS QUE GANHARAM O DIREITO DE SONHAR. Está, no topo da página, o texto imagético, a informação Ideal, o que pode ser. Abaixo, está a informação prática, mostrando o que é, o Real.

Os textos produzidos foram coletados pela professora, porém, não foi feito nenhum comentário geral a fim de que houvesse uma interação maior entre professora e alunos nas apreciações. Essa troca de ideias é de suma importância para o Letramento e para a construção de um sujeito crítico capaz de manifestar seu pensamento nas mais diversas situações de interlocução.

Passo à analise do questionário que foi respondido pelas professoras. Os nomes foram substituídos pelos seguintes códigos: $\mathbf{P 1}=$ professora n. 1, de Língua Portuguesa, e $\mathbf{P 2}=$ professora n. 2, a professora de Produção de texto.

À primeira pergunta do questionário: "De que maneira é feita a seleção dos textos explorados em sala de aula?":

1. P1 escreveu: "Os temas dos textos explorados em sala de aula sempre fazem parte do universo do aluno. A identificação do leitor com o assunto estudado é imprescindível para despertar o interesse pela leitura. Assim, os textos construídos pelos alunos têm um tema relevante para a realidade deles. O que observo quando os alunos escrevem é a presença da oralidade nos termos utilizados. Os erros ortográficos, de concordância e regência são constantes e denunciam a oralidade intrínseca no seu processo de produção de texto".

2. $\mathbf{P 2}$ afirmou que seleciona "textos que atendam a necessidade e realidade dos alunos, quanto à aprendizagem da língua materna e consequentemente, aprimorar o conhecimento da norma culta da língua”.(sic)

As respostas ilustram o processo seletivo que cada uma delas utiliza para os textos trabalhados em sala de aula. As entrevistadas declararam que optam por textos que façam parte do contexto sociocultural dos alunos, todavia, os textos trabalhados em sala de aula são extraídos do livro didático adotado pela escola e fornecido pelo MEC.

À pergunta dois: "Texto multimodal é aquele cujos significados se realizam por mais de um código semiótico; um texto, que, além dos elementos gráficos, possui imagem. Você costuma explorá-lo em sala de aula?"

1. P1 respondeu: "O texto multimodal é o texto que combina modos semióticos, incorporando imagens à escrita como forma de adaptar-se à realidade de constante mudança que ocorre no mundo. Atualmente, as imagens são indissociáveis da vida das pessoas e estão presentes, principalmente, através da TV e do computador. Os textos multimodais são a modernização dos textos, fazendo com que esses se tornem mais atraentes ao leitor". (sic)

2. P2 diz: "Costumo explorá-lo em sala de aula porque a imagem desenvolve a capacidade de percepção de mundo de cada aluno, uma vez que o valor semântico da imagem pode conduzir e 
ampliar a visão crítica do aluno, com mais fluidez e versatilidade" (grifos meus). (sic).

As respostas a essa pergunta revelaram que as pesquisadas não têm noção da teoria e da importância da Multimodalidade e não vêem a necessidade de interpretarmos os textos prestando atenção não apenas na língua escrita ou oral. Apenas P1 parece ter conhecimento da teoria, que, entretanto, não chega a ser explicitamente trabalhada por ela com seus alunos, o que foi confirmado em observações posteriores.

Para a questão três: "Você considera que o seu trabalho contribui para a construção crítica do discurso do aluno? De que maneira?"

1. P1 diz: "Os temas dos textos a serem trabalhados em sala de aula passam por um processo de escrita pelo aluno a partir da discussão sobre o tema. Há uma prévia leitura e correção do texto pelo professor, depois, há uma releitura e correção por parte do aluno. Os alunos leem os textos em voz alta, e a turma elege as melhores produções. Esse processo colaborativo faz com que os alunos despertem o interesse, participando do processo de seleção dos textos desde o início (grifo meu).

2. P2 escreveu: "Considero que meu trabalho contribui para a construção do discurso crítico do aluno porque o trabalho em sala de aula, com a Língua Portuguesa, tem como objetivo dar suporte e autonomia para o aluno desenvolver textos escritos e orais, ainda sistematizar a maneira do aluno realizar análise de textos e da vida". (grifos meus).

Os depoimentos das professoras pesquisadas parecem vislumbrar mudança ou consciência critica nas atividades desenvolvidas em sala de aula e considerar o conhecimento prévio dos alunos. $\mathrm{Na}$ primeira resposta, a professora afirma que busca temas e pontos de vista para discutir com os alunos considerando a experiência deles, promovendo a reformulação, a reconstrução e a amostragem nova do saber.

A segunda professora pesquisada dá preferência ao meio em que vive o aluno para que lhe seja dada autonomia, analisando textos que se identifiquem com a sua vida.

A quarta pergunta: "Qual a impressão que você tem de cada texto selecionado e explorado em sala de aula?" não foi respondida por nenhuma das entrevistadas.

Para a quinta pergunta: "Um sujeito letrado não sabe apenas ler e escrever, faz uso da leitura e da escrita em suas práticas sociais. Você já ouviu falar de estudos sobre Letramentos? Se sim, considera-os importantes? Por quê?"

1. P1 diz que: "Não tenho conhecimento dessa teoria linguística."

2. P2 diz que: "Talvez possa conhecer essa teoria, mas não com essa nomenclatura, portanto, não poderei dar o meu ponto de vista a respeito de tal teoria, sem ter utilizado-a" (sic). 
A primeira entrevistada não informou a respeito do conhecimento teórico que teria sobre os postulados do Letramento. Provavelmente, P2 não compreendeu a pergunta ou fez uma leitura inapropriada. As professoras parecem ignorar que as práticas sociais estão ligadas diretamente às práticas de Letramento que estão imersas em todos os contextos sociais; que os textos, quer sejam orais ou escritos, são parte indispensável das ocasiões de Letramento; que o estudo do Letramento é, parcialmente, um estudo de textos e de como eles são produzidos, distribuídos e consumidos.

A importância desses dados para a pesquisa está no fato de que há desconhecimento de teorias linguísticas importantes para os professores de Língua Portuguesa como ADC, Letramento e Multimodalidade e que, por isso mesmo, há a necessidade urgente de uma revisão das práticas docentes.

Percebeu-se, durante a análise dos dados que, apesar de haver a intenção de trabalhar textos imagéticos, tanto por parte do poder central (Ministério da Educação) como por parte das professoras, faltam-lhes o aparato teórico e metodológico apropriados para tais aulas. O fato de levarem para a sala de aula exemplos de textos multimodais pode ser visto como uma tentativa de levar os alunos a lerem não somente a linguagem escrita, mas também a visual, a simbólica, a icônica.

Kress (1996) afirma que língua(gem) e imagem não desempenham o mesmo papel. As imagens estão, sim, encarregando-se de certas funções anteriormente desempenhadas pela linguagem. As duas modalidades não estão meramente coexistindo. Há uma forte interação que pode, com o tempo, ter efeitos reais sobre a linguagem na modalidade escrita.

As crenças escolares sobre a leitura, limitadas apenas à compreensão da língua escrita, parecem ter depreciado o valor das outras formas de representação do mundo presentes na composição da mensagem escrita, sendo as demais tão portadoras de significado quanto esta. Refirome a todos os recursos de composição e de impressão do texto: imagens, cores, diagramação (layout) da página, formato das letras.

Como o texto deve ser lido conjugando-se todas as semioses nele presentes, todo esse conjunto de elementos deve ser levado em consideração, pois diz respeito à Multimodalidade das formas de representação. A língua, quer seja na modalidade falada, quer seja na modalidade escrita, não pode ser entendida senão em conjunto com outros modos de representação que participam da composição da mensagem. 


\section{Conclusão}

O objetivo deste artigo foi investigar se o texto multimodal é trabalhado em sala de aula e qual é a sua contribuição para a construção do discurso crítico do aluno. Ao final das reflexões, algumas considerações à luz dos dados analisados devem ser feitas.

Ao analisar as práticas discursivas utilizadas pelas professoras, percebe-se que as atividades eram meramente escolares e descontextualizadas, além disso, durante os eventos, as interações não ocorriam de maneira eficaz para que aluno pudesse manifestar seu pensamento. Sendo assim, posso concluir que o modelo de Letramento subjacente às práticas discursivas adotadas pelas professoras, no corpus selecionado, é o Modelo Autônomo de Letramento.

Tal modelo considera a aquisição da escrita como um processo neutro que, independentemente de considerações do contexto social, deve promover as habilidades necessárias para desenvolver no aluno a competência de interpretar e escrever textos abstratos, ou seja, há, naquele contexto, a reprodução do status quo pela escola. A escrita é completa em si mesma, não está presa ao contexto de sua produção para ser interpretada e há valorização do ato cognitivo em si.

Quanto à prática de sala de aula, se ela potencializa o aluno para a leitura de textos multimodais, está documentado que, naquele contexto, não o faz. O texto multimodal é usado como mero pretexto para o tradicional ensino da gramática da frase. Os textos foram apresentados e deles foram retirados apenas fragmentos para uma abordagem linguística que não foi além do horizonte da frase.

A modalidade escrita é apenas uma parte da mensagem. Em um texto, outros elementos advindos de outros tipos de semiose compõem-na. Concordo com Kress e van Leeuwen (1996) quando afirmam que qualquer texto escrito é multimodal, ou seja, composto por mais de um modo de representação. Em qualquer texto, além do modo linguístico, outras formas de representação estão presentes e não podem passar despercebidas, porque interferem na mensagem que se quer veicular. Nenhum modo deve ser visto isoladamente, os modos se complementam na composição do sentido.

A escolha de determinados modos em detrimento de outros deve ser entendida em relação ao uso que se pretende fazer. Uma vez que os produtores fazem as suas escolhas de acordo com seus interesses, o texto deve ser lido considerando o contexto histórico-social da sua produção.

Se o trabalho desenvolvido pelas professoras deveria contribuir para a construção crítica do discurso do aluno, os dados demonstram que não o fez, uma vez que, sequer são tratados assuntos como a ADC e o Letramento multimodal, que poderiam contribuir para o discurso crítico do aluno. O discurso constrói representações da realidade, estabelece relações sociais, cria, reforça e (re)constitui identidades (FAIRCLOUGH, 1992), sendo assim, o sentido do texto é caracterizado pelas diferenças existentes entre a imagem e o contexto social. As dimensões da prática linguística, 
da prática discursiva e da prática social parecem não ser do conhecimento dos docentes. O texto não é analisado como prática social. Vale ressaltar que o fenômeno do Letramento - como prática social - não é conhecido pelos docentes, tampouco subsidia a análise da conjuntura e das respectivas práticas sociais durante as discussões dos problemas sociais em sala de aula. Quanto à Multimodalidade, não são utilizados parâmetros para a observação dos elementos que compõem as imagens. Estas são vistas apenas como figuras, não como sintagmas visuais correspondentes aos que existem na sintaxe estrutural.

As demandas para a utilização bem-sucedida dos textos multimodais não se encerram no domínio das habilidades da língua escrita. As imagens que compõem um texto devem deixar de ser meras ilustrações; os recursos de diagramação e a formatação das letras devem deixar de ser um mero recurso para embelezar o texto. A imagem deve ser vista como parte do conteúdo de uma mensagem.

Dessa forma, o Letramento multimodal deve ser considerado uma forma de permitir que um número maior de pessoas tenha acesso à aprendizagem de habilidades de comunicação visual, dotando os sujeitos com ferramentas adequadas para realizar a leitura do mundo (FREIRE, 1987). Assim, o entrelaçamento do Letramento, da Multimodalidade e da ADC poderá ser a ferramenta capaz de potencializar os sujeitos para a leitura do mundo que contemple todas as formas de representação.

\section{Referências}

BARTON, D; HAMILTON, M. Literacy practices. In: BARTON, D; HAMILTON, M; IVANIC, R. Situated literacies: reading and writing in context. London, New York: Routledge, 2000.

. Everyday literacies. In: BARTON, D; HAMILTON, M. Local literacies: reading and writing in one community. London, New York: Routledge, 1998.

BAUER, M. W; GASKELL, G. Pesquisa qualitativa com texto, imagem e som. Petrópolis: Vozes, 2003.

CHOULIARAKI, L.; FAIRCLOUGH, N. Discourse in late modernity. Cambridge: University Press, 1999.

FAIRCLOUGH, N. Discourse and social change. Cambridge: Polite Press, 1992.

Discurso e mudança social. Trad. de I. Magalhães. Brasília: UnB, 2001.

Analysing Discourse: textual analysis for social research. London, New York: Routledge, 2003.

FAIRCLOUGH, N; WODAK, R. Análisis crítico del discurso. In: van Dijk, T. A. (Comp) El discurso como interacción social. Barcelona: Gedisa, 2001

FLICK, U. Uma introdução à pesquisa qualitativa. Porto Alegre: Bookman, 2004.

FRASCOLLA, A; FÉR, A. S; PAES, N.S. Lendo e interferindo. $7^{\text {a }}$ série. São Paulo: Moderna, 1999.

HASAN, R; WILLIAMS, G. Literacy in society. London, New York: Longman, 1996.

HEATH, S. B. What no bedtime story means: narrative skills at home and school. Language in Society v. 11, 1982, p. 49-76.

. Ways with words: language, life, and work in communities and classrooms. Cambridge: Cambridge University Press, 1983.

KLEIMAN, A. B. (Org.). Os significados do letramento: uma nova perspectiva sobre a prática social da escrita. Campinas: Mercado de letras, 1995.

KRESS, G; van LEEUWEN. Multimodal discourse: the modes and media of contemporary communication. New York: Oxford Press, 2001. Reading images: the grammar of visual design. London: Routledge, 1996.

KRESS, G; LEITE-GARCIA, R; van LEEUWEN, T. Semiótica discursiva. In: El discurso como estructura y proceso: estudios sobre el discurso - una introducción multidisciplinaria. Compilado por Teun van Dijk. España: Gedisa, 2000

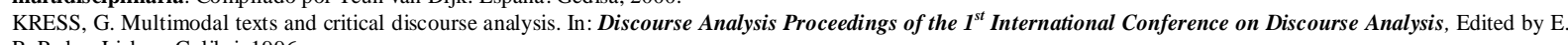
R. Pedro. Lisboa: Colibri, 1996.

MARCUSCHI, L. M. Da fala para a escrita: atividades de retextualização. São Paulo: Cortez, 2004.

SILVA, D.E.G; VIEIRA, J.A. Práticas de análise do discurso. Brasília: Plano, 2003.

STREET, B. V. Literacy in theory and practice. Cambridge: University Press, 1984.

. Cross-cultural approaches to literacy. Cambridge: University Press, 1993.

Social literacies: critical aproaches to literacy in development, ethnography and education. London: Longman, 1995.

$\overline{T A N N E N}, \bar{D}$. (Ed.) Spoken and written language: exploring orally and literacy. Norwood: N. J. Ablex, 1982.

TREVISAN, A. L. Pedagogia das imagens culturais. Ijuí: Unijuí, 2002.

VIEIRA, J. A. Novas perspectivas para o texto: uma visão multissemiótica. In: Reflexões sobre a língua portuguesa: uma abordagem multimodal. Petrópolis: Vozes, 2007. 